\title{
SOCIODRAMA COM ESTUDANTES UNIVERSITÁRIOS NO CONTEXTO DA PANDEMIA POR COVID-19
}

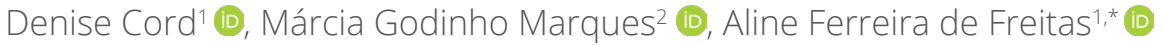

\section{RESUMO}

Em 2020, os sistemas educacionais de diversos países foram afetados pela pandemia de Covid-19. No Brasil, o Ministério da Educação autorizou a substituição de aulas presenciais por aulas em meios digitais. Relata-se a experiência em um projeto de estágio em Psicologia Escolar e Educacional com base na metodologia sociodramática e foco nas condições simbólicas de permanência e sucesso escolar vinculadas ao desenvolvimento do papel de estudante universitário em tempos de Ensino Remoto Emergencial.

PALAVRAS-CHAVE: Sociodrama; Ensino Superior; Universidade; Ensino Remoto Emergencial.

\section{SOCIODRAMA WITH UNIVERSITY STUDENTS IN THE CONTEXT OF THE COVID-19 PANDEMIC}

\begin{abstract}
In 2020, the educational systems of several countries have been affected by the Covid-19 pandemic. In Brazil, the Education Ministry allowed the substitution of in person classes for classes in digital environments. We report our experience in an academic internship project in educational psychology based on the sociodramatic methodology and a focus on permanence and academic success as symbolic conditions linked to the development of the role of university student in times of Emergency Remote Teaching.

KEYWORDS: Sociodrama; Higher education; University; Emergency Remote Teaching.

\section{SOCIODRAMA CON ESTUDIANTES UNIVERSITARIOS EN EL CONTEXTO DE LA PANDEMIA COVID-19}

\section{RESUMEN}

En 2020, los sistemas educativos de varios países fueran afectados por la pandemia de Covid-19. En Brasil, el Ministerio de la Educación autorizó la sustitución de las clases presenciales por clases en medios digitales. La experiencia en un proyecto de pasantía en Psicología escolar y educativa se relata con base en la metodología sociodramática y se enfoca en las condiciones simbólicas de permanencia y éxito escolar vinculadas al desarrollo del rol del estudiante universitario en tiempos de Educación Remota de Emergencia.

PALABRAS CLAVE: Sociodrama; Educación Superior; Universidad; Educación Remota de Emergencia.

1.Universidade Federal de Santa Catarina - Departamento de Psicologia - Florianópolis (SC), Brasil.

2.Pesquisadora autônoma - Florianópolis (SC), Brasil.

*Autora correspondente: fr.alinef@gmail.com

Editor de Seção: Rosely Cubo

Recebido: Dez. 14, 2020 | Aceito: Jan. 20, 2020 


\section{INTRODUÇÃO}

As últimas décadas foram marcadas pela expansão significativa do número de ingressantes no Ensino Superior brasileiro. Observa-se, a partir dos anos 90, a implantação de diversas políticas de democratização do acesso, dentre elas o sistema de cotas proveniente das ações afirmativas de inclusão, o Programa Universidade para Todos (Prouni) e o Fundo de Financiamento Estudantil (Fies) (Salata, 2018). Por outro lado, as condições materiais e simbólicas de permanência em instituições de Ensino Superior têm sido apontadas como um ponto frágil (Santos, 2009).

Em 2020, os sistemas educacionais de diversos países foram afetados pela pandemia de Covid-19. De acordo com a Organização das Nações Unidas para a Educação, a Ciência e a Cultura (Unesco), houve fechamento generalizado das instituições de ensino em mais de 150 países (Unesco, 2020). No Brasil, após declaração de emergência em saúde pública de importância nacional em decorrência da Covid-19 (Ministério da Saúde, 2020), foi oficializada pelo Comitê Operativo de Emergência do Ministério da Educação (COE-MEC) a Portaria n. 343/2020, que autoriza a substituição de aulas presenciais por aulas em meios digitais (Ministério da Educação, 2020).

Estabelecer tais condições de funcionamento exigiu das universidades, especialmente dos setores de assistência estudantil, respostas rápidas para o enfrentamento das questões sociais que ficaram mais acentuadas (Gomes \& Pereira, 2020). Como os dados sobre permanência estudantil durante a pandemia ainda são escassos, não é possível determinar se as medidas adotadas pelas universidades foram eficazes. Visto que as políticas de permanência estudantil envolvem muitos fatores, neste estudo propõe-se discutir, a partir da prática da psicologia escolar e educacional, bem estar e sucesso escolar como condições simbólicas de existência vinculadas ao desenvolvimento do papel de estudante universitário em tempos de pandemia e Ensino Remoto Emergencial (ERE).

J. L. Moreno foi o criador da teoria socionômica da qual deriva a sociatria, que consiste na intervenção terapêutica em relações sociais. O sociodrama compõe essa teoria e foi a abordagem utilizada no desenvolvimento do projeto ao qual este relato se refere. É um tipo de intervenção com fins terapêuticos na qual o protagonista é o grupo, reunido por um objetivo em comum (Gonçalves et al., 1988).

\section{MÉTODO}

O projeto consistiu na oferta de grupos de acolhimento para estudantes universitários, por meio da plataforma de reuniões Google Meet. A partir da divulgação em sites e fóruns da universidade, estudantes foram convidados a se inscrever nas atividades do projeto, que compreendiam a realização de pelo menos três encontros com duração de uma hora e meia. Os encontros foram planejados e desenvolvidos de acordo com as três etapas do sociodrama: aquecimento, dramatização e compartilhamento (Souza \& Drummond, 2018). As análises e o planejamento dos encontros foram norteados principalmente pelo estudo da teoria dos papéis e da teoria da ação. Buscou-se, portanto, coordenar ações a partir da dinâmica vincular do desempenho de um papel mediante seu contrapapel, de modo a alterar obstáculos ao seu desempenho no ato dramático (Gonçalves et al., 1988).

Visto que o desempenho do papel de estudante universitário pode propiciar conflitos com influência no sucesso escolar, considera-se que o trabalho sociodramático auxilia no processo de aprendizagem do papel e no desenvolvimento de repertórios espontâneos e criativos (Cord et al., 2020). Durante os encontros foram empregadas técnicas com objetivo de auxiliar na construção e no desenvolvimento dos temas protagônicos do grupo. Utilizaram-se recursos de mídia (fotos e vídeos) e aplicativos auxiliares (Jamboard) no desenvolvimento de técnicas que possibilitaram a dramatização do papel de estudante universitário.

\section{RELATOS E DISCUSSÃO}

Logo após a suspensão das atividades presenciais na Universidade Federal de Santa Catarina, várias pautas acerca das condições necessárias para a implantação do ensino remoto foram oficialmente movimentadas. A princípio, os debates focaram majoritariamente as diretrizes indicadas no documento do Ministério da Educação sobre ensino a distância (Ministério 
da Educação, 2007). No entanto, visto que a situação demandaria a implantação de um regime emergencial de ensino, as diretrizes sobre ensino a distância (EAD) não foram suficientes. Portanto, as discussões se encaminharam para questões pertinentes à permanência estudantil e à garantia da qualidade da formação acadêmica, de modo a considerar a diversidade das atividades necessárias para o alcance dessa meta. Gusso et al. (2020) destacam nove condições necessárias para viabilizar a educação superior de qualidade durante a pandemia. Dentre elas, as que melhor relacionam-se com a experiência neste projeto são: acesso à internet e qualidade de conexão; repertório de professores e estudantes para manejar a plataforma de ensino; características do ambiente de trabalho e estudo; tipos de dificuldade que professores e estudantes estão enfrentando; expectativas que cada pessoa envolvida no processo de ensino e aprendizagem possui em relação a esse processo.

Ao participarem dos encontros do projeto, estudantes relataram mudanças abruptas em suas rotinas, como dificuldades de adaptação à nova configuração da casa (ex.: aqueles que voltaram a viver com seus pais e mães) e dificuldades materiais (ex.: falta de equipamentos adequados). A "quebra de expectativas" causada pela pandemia e por essas mudanças que impactaram diretamente as expectativas e objetivos dos estudantes para o ano de 2020 foi tema frequente durante os encontros. A ausência de controle acerca da situação de isolamento social causada pela pandemia, somada à presença dessas expectativas frustradas, foram relatadas como barreira para a criação de novos objetivos. A fala de um dos participantes ilustra esta questão: "Eu participei de várias coisas, fiz coisas que acho que, se não fosse a pandemia, eu não teria a oportunidade de fazer, mas mesmo assim sinto que não estou entregando o que deveria”. Weiner (1990) indica que as teorias da motivação mais recentes consideram as crenças de autoeficácia e os objetivos como importantes determinantes, podendo-se afirmar que essa barreira, que dificulta a criação de novos objetivos pelos estudantes, tem impacto direto em sua motivação.

Moreno, por sua vez, afirma que criatividade, espontaneidade e sensibilidade são recursos inatos do ser humano, mas que alguns ambientes e contextos sociais são desfavoráveis ao desenvolvimento desses recursos, sendo através da ação transformadora que ocorre a recuperação desses fatores vitais. A espontaneidade é definida pela capacidade de responder adequadamente a novas situações (Moreno, como citado em Gonçalves et al., 1988, p. 45). O tipo de adequação que propõe Moreno, segundo Gonçalves et al. (1988), não se refere a um ajustamento e a uma manutenção daquilo que já está concebido, mas sim à "adequação e ajustamento do homem a si mesmo" (p. 47). Respostas espontâneas potencializam a criatividade, definida pela capacidade de "produzir, a partir de algo que já é dado, alguma coisa nova" (Gonçalves et al., 1988, p. 47). A espontaneidade e a criatividade são colocadas como ferramentas para romper com as conservas culturais, entendidas como "comportamentos, usos e costumes, que se mantêm idênticos, em uma dada cultura" (Gonçalves et al., 1988, p. 48). Partindo dessa teoria, é possível afirmar que a situação de isolamento social e todas as decorrências dela, incluindo o ERE, exigem dos indivíduos respostas adaptadas para o contexto. Portanto, os estudantes precisam modificar suas metas e objetivos, de modo a criar novas ações condizentes com a situação.

É importante salientar que essas novas ações modificam outras que estavam conservadas na cultura da universidade e que por um longo período foram úteis e possivelmente espontâneas, pois cada nova ação, ainda que espontânea, pode se tornar parte de uma conserva quando os indivíduos passam a apenas reproduzir o que foi criado. Logo, o espaço de reflexão acerca da necessidade de criação de novas respostas, ainda que não se chegue em um consenso sobre qual é a melhor resposta para uma situação, já propicia aos participantes uma nova perspectiva sobre seus potenciais de transformação do meio. Em um dos encontros, cada um dos participantes deu uma solução para um problema em cena. No momento em que foi solicitado que eles decidissem o rumo da cena, essa reflexão acerca da necessidade de adaptação de antigas respostas ficou evidente. A resposta criada em cena foi espontânea, no entanto, impossível de ser generalizada. Ainda assim, os participantes lançaram um novo olhar para a situação, visto que se depararam com suas ações conservadas e a necessidade de modificá-las.

Ademais, o que parece afetar a motivação dos estudantes não é só a dificuldade de formular metas e objetivos, mas também de adaptar-se às novas formas de ensino e aprendizagem que se estabelecem com o ERE. Como citado anteriormente, as crenças de autoeficácia são determinantes da motivação. Nesse sentido, observou-se que os estudantes relatam uma percepção de não ter o que é preciso para ser estudante universitário no atual contexto. Alain Coulon (2017) indica que é fundamental para o sucesso do estudante universitário o processo de afiliação, caracterizado quando o indivíduo se apropria do ofício de estudante universitário ao transformar instruções acerca do trabalho universitário em ações práticas. 
Essa nova competência, em processo de construção, se manifesta por meio de diversos marcadores de afiliação: expressão escrita e oral, inteligência prática, seriedade, ortografia, presença de referências teóricas e bibliográficas nos trabalhos escritos, utilização espontânea do futuro anterior anunciador de uma perspectiva em construção. Ele começa a categorizar o mundo intelectual, no qual entrou alguns meses antes, da mesma maneira que os outros membros e, sobretudo, da maneira como os seus professores esperam que ele faça (p. 1247).

Durante um dos encontros, foi proposta uma cena na qual os participantes precisavam trocar habilidades uns com os outros. Foi solicitado que eles pensassem em habilidades que gostariam de desenvolver e indicassem colegas que consideravam possuí-las. Também foi solicitado que eles notassem quais habilidades tinham e que poderiam trocar com os demais. Ao serem escolhidos pelos colegas, os participantes reconheceram suas próprias habilidades e potencialidades, de modo a aumentar o senso de autoeficácia e consolidar o processo de afiliação. Ademais, é comum nos relatos dos estudantes a afirmação de que o ERE exige uma participação mais ativa, pois a aferição de frequência, que antes era garantida pela presença nas aulas, agora é realizada por meio de atividades e/ou interações nos fóruns das disciplinas. Portanto, ainda que as habilidades das quais os participantes sentiam falta (ex.: criatividade, organização) não sejam relacionadas exclusivamente ao ERE, algumas demandas requerem um uso diferente delas, ressaltando mais uma vez a necessidade de criação nos moldes descritos por Moreno.

Por fim, a necessidade de convivência com os pares também foi um tema recorrente nos encontros. Segundo Bustos (1990), a maioria das relações que os indivíduos estabelecem na vida adulta é simétrica, sem predomínio de forças ou poder, e constitui o cluster fraterno. Esse tipo de relação marca o desenvolvimento de uma terceira dinâmica de interação - em contraposição às dinâmicas passiva e ativa encontradas nos clusters materno e paterno. Nesse sentido, quanto mais diversas forem as possibilidades de convivência com os pares para o estudante universitário, mais saudável será o desenvolvimento desse papel. Durante os encontros, os participantes deram muita ênfase à função de acolhimento e compartilhamento que a interação com os outros estudantes universitários possibilita. Muitos estudantes apontaram o próprio grupo como alternativa para experienciar essa troca, visto que o ambiente acadêmico propicia uma postura individualista. No entanto, em um dos encontros a interação competitiva com os pares foi colocada de forma positiva, pois favorece o desenvolvimento de autonomia

\section{CONSIDERAÇÕES FINAIS}

Considera-se que esta experiência contribuiu para a compreensão das condições materiais e subjetivas de permanência e de desenvolvimento do papel social de estudante na universidade em tempos de pandemia e de ensino remoto emergencial. Ainda que os grupos tivessem função de acolhimento, é notável que um repertório de ações mais espontâneas foi desenvolvido pelos participantes em relação ao desempenho desse papel.

Em relação aos resultados dessa experiência, recomenda-se que a universidade, a partir da mediação de psicólogos(as) vinculados aos serviços de atenção aos estudantes, exerça um papel mais ativo na escuta e orientação dos estudantes, especialmente enquanto persistir a modalidade de ensino remoto emergencial. O oferecimento de grupos de acolhimento voltados para o planejamento de carreira, organização de estudos e manejo do tempo também pode auxiliar os estudantes a formular novos objetivos e criar formas de estudos que façam sentido para cada um, além de possibilitar o compartilhamento e a troca de experiências entre os pares.

Por fim, o desenvolvimento deste projeto contribuiu para o desenvolvimento do papel profissional da autora, uma vez que proporcionou experiência prática de direção e planejamento de grupos terapêuticos na modalidade online, bem como a criação, testagem e avaliação de novas formas de atuação profissional junto aos estudantes do ensino superior.

\section{CONTRIBUIÇÃO DAS AUTORAS}

Conceitualização: Cord D, Marques MG, Freitas AF; Investigação: Freitas AF; Escrita: Cord D, Freitas AF. 


\section{AGRADECIMENTOS}

Não se aplica.

\section{DISPONIBILIDADE DE DADOS DE PESQUISA}

Não se aplica.

\section{FINANCIAMENTO}

Não se aplica.

\section{REFERÊNCIAS}

Bustos, D. M. (1990). Perigo... amor à vista: Drama e psicodrama de casais. Aleph.

Cord, D., Marques, M. G., Freitas, A. F., Marques, C., \& Demasi, G. (2020). Laboratório da Ação: Desenvolvendo repertório espontâneo e criativo para uma trajetória de formação profissional saudável. In M. S. J. Lucas, \& L. R. C. Feitosa (Orgs.), Reflexões sobre orientação profissional, trajetórias escolares e carreiras: Perspectivas e desafios. CRV, Curitiba.

Coulon, A. (2017). O ofício de estudante: A entrada na vida universitária. Educação e Pesquisa, 43(4), 1239-1250. https://doi.org/10.1590/s1517-9702201710167954

Gomes, A. M. O., \& Pereira, S. C. S. (2020). Reconfigurações do trabalho de assistentes sociais na política de educação em tempos de pandemia: Considerações a partir de vivências no IFPI. In S. L. B. Pereira, \& I. H. G. M. Cronemberger (Orgs.), Serviço social em tempos de pandemia: Provocaçôes ao debate. EDUFPI.

Gonçalves, C. S., Wolff, J. R., \& Almeida, W. C. (1988). Liçôes de Psicodrama: Introdução ao pensamento de J. L. Moreno. Ágora.

Gusso, H. L., Archer, A. B., Luiz, F. B., Sahão, F. T., Luca, G. G., Henklain, M. H. O., Panosso, M. G., Kienen, N., Beltramello, O., \& Gonçalves, V. M. (2020). Ensino superior em tempos de pandemia: Diretrizes à gestão universitária. Educą̧ão E̊ Sociedade, 41, e238957. https://doi.org/10.1590/es.238957

Ministério da Educação. (2007). Referenciais de qualidade para educação superior a distância. Secretaria de Educação a Distância. Disponível em: http://portal.mec.gov.br/seed/arquivos/pdf/legislacao/refead1.pdf

Ministério da Educação. (2020). Portaria n. 343, de 17 de março de 2020. Diário Oficial da União, ed. 53, seção 1. https:/www.in.gov.br/en/web/dou/-/portaria-n-343-de-17-de-marco-de-2020-248564376

Ministério da Saúde. (2020). Portaria n. 188, de 3 de fevereiro de 2020. Diário Oficial da União, ed. 24-A, seção 1. http://www.in.gov.br/en/web/dou/-/portaria-n-188-de-3-de-fevereiro-de-2020-241408388

Salata, A. (2018). Ensino Superior no Brasil das últimas décadas: Redução nas desigualdades de acesso? Tempo Social, 3O(2), 219-253. https://doi.org/10.11606/0103-2070.ts.2018.125482

Santos, D. B. R. (2009). Para além das cotas: A permanência de estudantes negros no ensino superior como política de ação afirmativa [Tese de Doutorado, Universidade Federal da Bahia].

Souza, A. C., \& Drummond, J. (2018). Sociodrama na Educação. Wak.

Unesco. (2020). COVID-19 educational disruption and response. http://www.iiep.unesco.org/en/covid-19-educationaldisruption-and-response-13363

Weiner, B. (1990). History of motivational research in education. Journal of educational Psychology, 82(4), 616. https:// doi.org/10.1037/0022-0663.82.4.616 